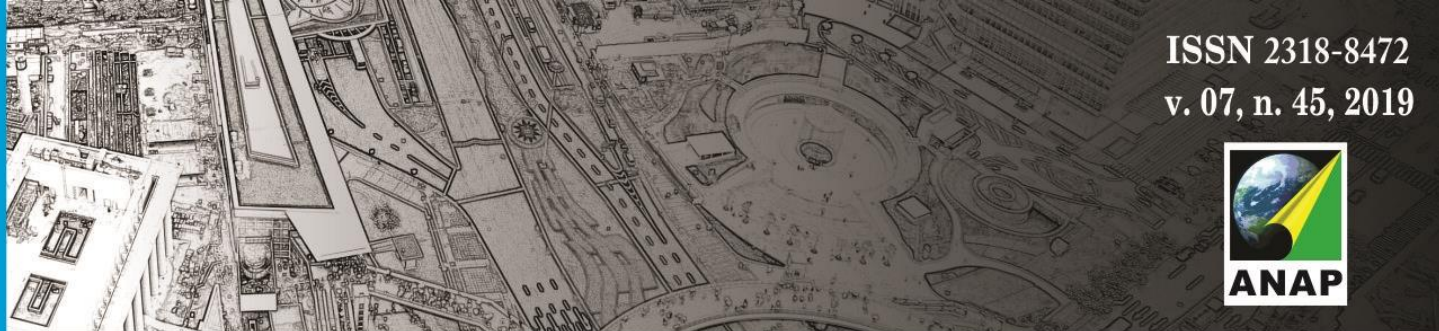

Revista Nacional de Gerenciamento de Cidades

\title{
A cidadania na construção coletiva do território. Casos de Estudo: Portimão e Loulé
}

The citizenship in the collective construction of the territory. Studies Case: Portimão and Loulé

La ciudadanía en la construcción colectiva del territorio. Casos de estudio: Portimão y Loulé

Lucinda Oliveira Caetano Investigadora CIAUD, Universidade de Lisboa, Portugal lucinda.caetano63@gmail.com

José Crespo

Professor Doutor, Universidade de Lisboa, Portugal jcrespo@fa.utl.pt

Luis Manata e Silva

Investigador CICS.NOVA, Universidade Nova de Lisboa, Portugal Imanata@gmail.com 

digital" como recurso para a divulgação de mais e "melhor" informação (simplificação técnica e utilização intuitiva) e enquanto canal de participação capaz de promover a verdadeira interação - comunicação nos dois sentidos -, entre as organizações e os utilizadores, sem descurar as necessidades da população que não "domina" as tecnologias digitais.

Cabe aqui um parêntesis para chamar a atenção para o nosso mundo globalizado, onde o quotidiano é cada vez mais visível (e vivido) nas redes sociais e as tecnologias digitais estão sendo usadas para criar várias oportunidades para o cidadão interagir com as instituições nos diferentes níveis político, económico e social. De governos locais a regionais e nacionais, de administrativos a políticos, há um número crescente de canais para diferentes níveis de participação. Há uma tendência mundial para a adoção de tecnologias digitais pela administração pública na forma de aplicativos móveis baseados na Web, modelagem e simulação digital e plataformas digitais, que permitem a interatividade ou a interação.

Portugal não é exceção, na medida em que a legislação do país contempla a utilização de plataformas de gestão territorial colaborativas. Na rotina diária das administrações locais, no entanto, essas tecnologias e plataformas raramente são usadas. A participação do público em geral em Portugal já é muito baixa, assistida digitalmente ou não; no entanto, 33\% da população total não é considerada proficiente no uso de tecnologias digitais para tarefas participativas. Uma exclusão digital que pode representar um risco no futuro próximo, pois vários processos potencialmente tornar-se-ão totalmente digitais. O "analfabetismo digital" é agora maior do que o "analfabetismo regular" durante o período da ditadura portuguesa, e não há nenhum esforço visível para permitir que a população supere essa divisão e lacuna.

A ação centrada no território, desenvolvida em parceria com Associações Locais, subdividiu-se em três iniciativas - Workshop sobre Identidade Urbana; Tertúlia sobre Revitalização Urbana e Partilha de Boas Práticas e Workshop sobre Participação Pública (incluindo a manipulação das plataformas digitais dos Municípios dos casos de estudo).

No presente artigo apresentam-se os resultados obtidos nos Workshops sobre Participação Pública, denominados "A Cidadania na Construção Coletiva do Território», realizados em Portimão (03 de março de 2018) e em Loulé (19 de maio de 2018).

Considerando o contexto específico de cada caso de estudo, incluindo o diálogo existente em 2018 entre a sociedade civil e os representantes políticos, foram elaboradas parcerias do CIAUD - Centro de Investigação em Arquitetura, Urbanismo e Design - da Faculdade de Arquitetura da Universidade de Lisboa com alguns organismos locais.

Em Portimão a parceria foi feita apenas com duas Associações da Sociedade Civil - Teia D'Impulsos e Contramaré - porque existe um distanciamento acentuado entre o poder político e a sociedade civil e provavelemente se incluíssemos a Câmara Municipal como parceira (caso a mesma aceitasse) não teríamos os atores independentes que desejávamos.

No caso de Loulé existe um maior envolvimento entre o poder político e a população local, verificável em situações concretas, tais como: formato das reuniões de Câmara que são bastante informais; sessões da Assembleia Municipal transmitidas pela internet; sessões de esclarecimento com formato e em número mais alargado do que o previsto no Regime Jurídico de Instrumentos de Gestão Territorial (RJIGT); recurso a instrumentos da democracia participativa - orçamento participativo. Portanto, o mais coerente seria que para além das Associações da Sociedade Civil - Casa da Cultura de Loulé e Delegação de Loulé da ACRAL (Associação do Comércio e Serviços da Região do Algarve) - fosse proposta uma parceria com a Câmara Municipal de Loulé (que prontamente aceitou). Por outro lado, a experiência de 
Portimão mostrou-nos a necessidade de incluir jovens nos Workshops, razão pela qual se fez o convite à Escola Secundária de Loulé. No entanto, apesar dos jovens terem comparecido ao primeiro Workshop e terem dado um excelente contributo, não apareceu nenhum jovem no Workshop sobre cidadania, devido a questões logísticas internas da própria Escola.

O conteúdo dos Workshops "A Cidadania na Construção Coletiva do Território» baseou-se em discussões sobre as diversas tipologias de participação pública, a cidadania responsável e os canais de participação existentes formais e informais, havendo uma componente prática de apropriação dos instrumentos e reflexão sobre a temática.

Utilizámos como suporte os resultados obtidos em sub-investigações sobre participação pública nos vários canais democráticos formais e informais, tanto da democracia representativa quanto da democracia participativa, tais como, Reuniões de Câmara, Sessões de Assembleia Municipal, Participação no âmbito dos Instrumentos de Gestão Territorial e processos de Orçamento Participativo, em especial no território algarvio (CAETANO et al., 2018).

Os resultados comprovam os baixos índices participativos. Nas entrevistas semiestruturadas a atores-chave da sociedade civil (para procurar identificar as razões dessa situação) foram citadas as seguintes causas possíveis: falta de tradição participativa; individualismo (falta de responsabilização com o futuro do território); sensação de que a opinião do cidadão não é tida em conta; medo de retaliação por parte dos dirigentes políticos e técnicos; linguagem técnica hermética; desinteresse pela política e desconfiança relativamente aos representantes políticos. Complementarmente elaborou-se um inquérito exploratório que fosse representativo de tendências de determinados grupos sociais, utilizadores do espaço em estudo, e com predisposição à participação, recolhidos no primeiro Workshop e em ações culturais e cívicas. No caso de Portimão, o inquérito foi estruturado em três partes distintas: Caracterização dos Inquiridos, Predisposição à Participação e eventuais Causas para a não Participação, utilizando um conjunto de questões fechadas, mas deixando algumas perguntas abertas, para permitir a partilha de ideias.

No caso de Loulé (posterior em termos temporais), no âmbito da temática da Governança digital, acrescentou-se uma quarta parte referente à Utilização da Plataforma Digital do Município.

A primeira parte - Caracterização dos inquiridos - procurou traçar o perfil do inquirido (idade, escolaridade, posição social e vinculação ao "lugar" - natural, morador ou trabalhador). A segunda parte - Predisposição à Participação - procurou avaliar o interesse pessoal em participar civicamente e em caso positivo, através de que canais. A terceira parte - Causas para a não Participação - enquanto cerne do conteúdo exploratório foi subdividida em duas abordagens distintas:

- uma primeira em questões fechadas onde se encontravam elencadas as causas citadas nas entrevistas semiestruturadas para a não participação pública;

- uma segunda que procurou deixar em aberto a possibilidade de o inquirido referir outras razões.

No caso de Loulé a quarta parte, referente à utilização da Plataforma Digital, procurou aferir se essa ferramenta era utilizada e se era "facilmente" compreendida pelos utilizadores.

Relativamente ao total de inquéritos em Portimão foram preenchidos quarenta e um (41), distribuídos entre naturais e residentes, numa faixa etária preponderante alargada (entre os 20 e os 60 anos), com escolaridade maioritariamente de grau superior; enquanto em Loulé foram inquiridos dezoito (18) pessoas, também distribuídos entre naturais e residentes, inseridos 


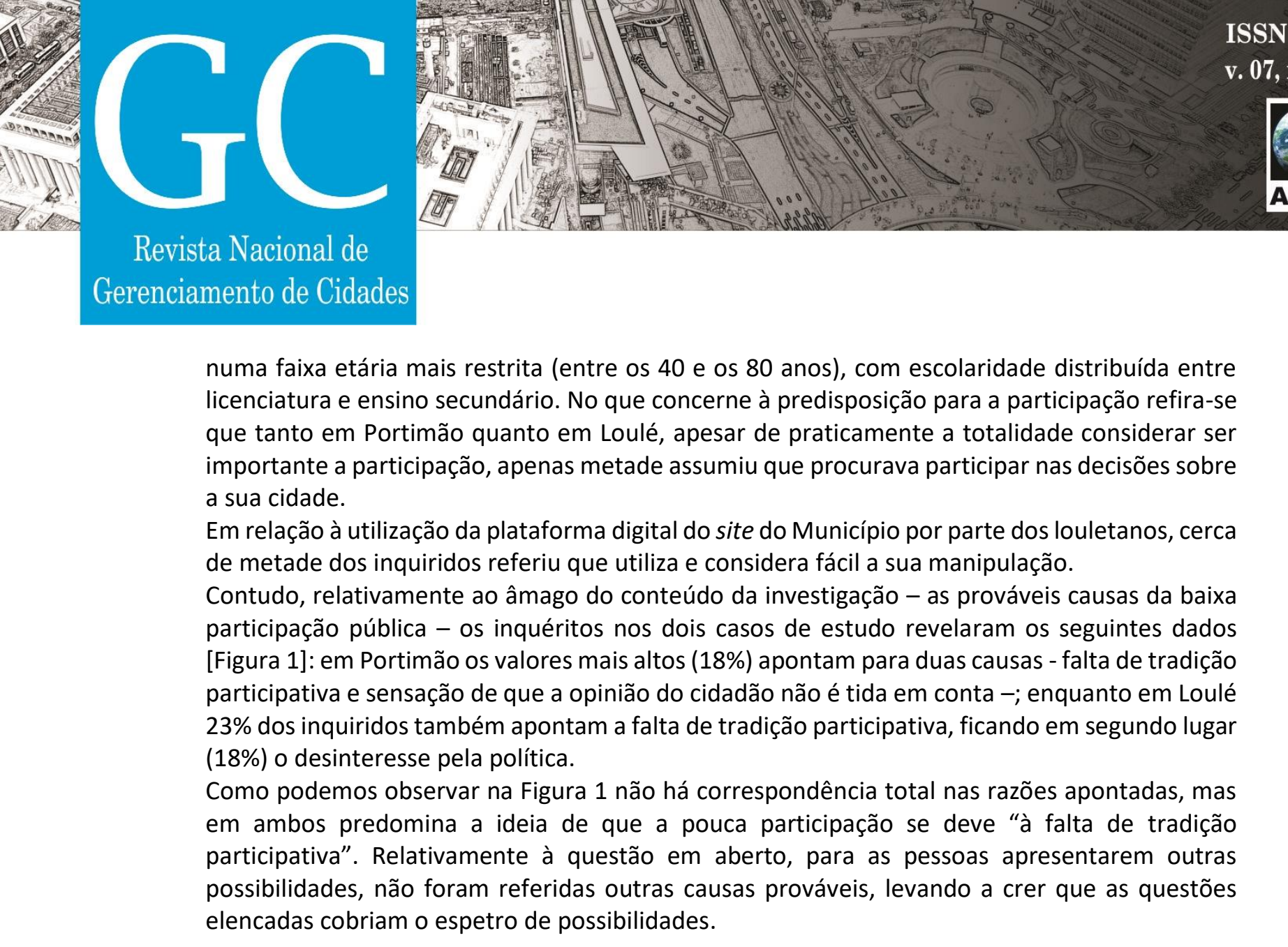

numa faixa etária mais restrita (entre os 40 e os 80 anos), com escolaridade distribuída entre licenciatura e ensino secundário. No que concerne à predisposição para a participação refira-se que tanto em Portimão quanto em Loulé, apesar de praticamente a totalidade considerar ser importante a participação, apenas metade assumiu que procurava participar nas decisões sobre a sua cidade.

Em relação à utilização da plataforma digital do site do Município por parte dos louletanos, cerca de metade dos inquiridos referiu que utiliza e considera fácil a sua manipulação.

Contudo, relativamente ao âmago do conteúdo da investigação - as prováveis causas da baixa participação pública - os inquéritos nos dois casos de estudo revelaram os seguintes dados participativa e sensação de que a opinião do cidadão não é tida em conta -; enquanto em Loulé a ntam a falta de tradição participativa, ficando em segundo lugar (18\%) o desinteresse pela política.

Como podemos observar na Figura 1 na em ambos predomina a ideia de que a pouca partici participativa". Relativamente à questão em aberto, para as pessoas apresentarem outras elencadas cobriam o espetro de possibilidades.

Figura 1 - Gráficos com as percentagens das causas apontadas pelos inquiridos nos casos de estudo

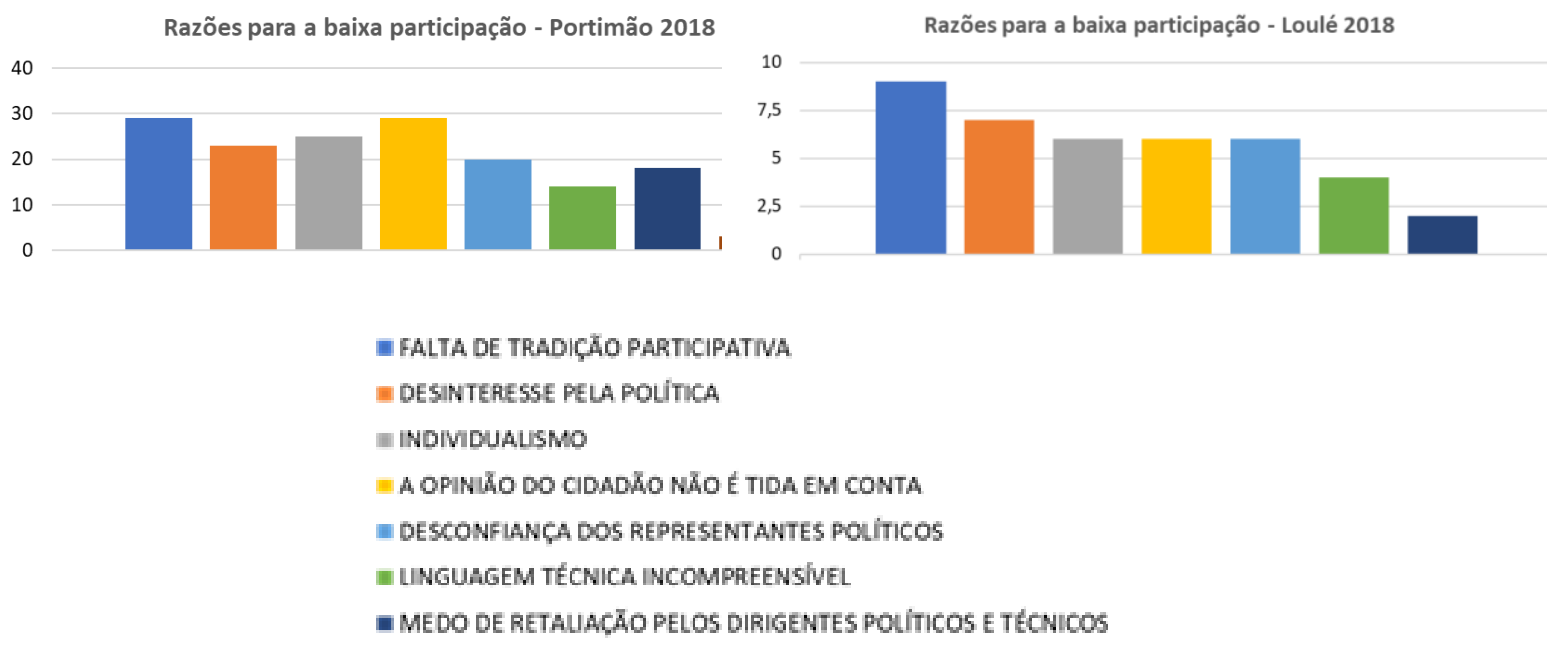

Fonte: Elaborados pelos autores, com base nos resultados dos inquéritos.

\section{METODOLOGIA}

A metodologia proposta para os Workshops dos dois casos de estudo baseou-se em dois momentos distintos:

- Num primeiro, foram apresentados e discutidos conteúdos relacionados com a participação pública e a cidadania responsável, tais como: partilha de exemplos de boas práticas de modelos e ferramentas de participação pública; apresentação dos instrumentos de gestão territorial em vigor (explicitando o significado de definições técnicas a nível urbanístico); 
Revista Nacional de

demonstração de que não há uma relação direta entre parâmetros urbanísticos e qualidade urbana, porque há outras variáveis a considerar (como por exemplo a forma urbana); o debate sobre as diversas tipologias de participação pública e os canais de participação formais e informais, existentes, físicos e digitais (incluindo a demonstração da manipulação do site do Município).

- Num segundo momento, os participantes/ convidados foram divididos em grupos com o objetivo de selecionarem uma ideia prioritária (retirada do Workshop anterior sobre Identidade e a Forma Urbana) para a revitalização do centro antigo da cidade a ser apresentada através de um dos canais de participação "formais" ou "informais" disponíveis (selecionado na sequência de um debate dentro do grupo de trabalho) com posterior reflexão sobre a pertinência da ideia e do canal de participação, usando uma ferramenta de análise de Thinking Design, mais especificamente, uma tipologia de The Customer Journey Map, criado pelos autores para o efeito.

Considerando as especificidades de cada contexto de investigação - território e população local - o conteúdo "apesar de fundamentar-se na mesma abordagem" e prever a utilização do mesmo método de trabalho - CUSTOMER JOURNEY MAP - seguiu caminhos absolutamente distintos, relativamente ao percurso e aos temas abordados, ainda que em termos de participação do público tenha sido mantido um padrão de redução drástica, relativamente aos primeiros Workshops sobre a Identidade e Forma Urbana dos centros antigos e às Tertúlias sobre a partilha de boas práticas de revitalização dos centros antigos.

No caso de Portimão a participação reduziu-se de vinte e cinco (25) cidadãos, para além dos seis (6) facilitadores, no 1. Workshop e quarenta (40) pessoas na Tertúlia para oito (8) participantes, mais oito (8) facilitadores no Workshop sobre Participação Pública.

Em Loulé a participação sofreu alterações ainda mais radicais (apesar de ter-se reduzido o tempo do segundo Workshop para meio dia) começou-se no 1. - Workshop com trinta e seis (36) cidadãos, para além dos oito (8) facilitadores, e cerca de vinte (20) pessoas na Tertúlia para nove (9) participantes, distribuídos da seguinte maneira: cinco (5) técnicos municipais, dos quais três (3) foram apresentar as ferramentas de participação urilizadas, dois (2) parceiros, dois (2) munícipes, e dois (2) facilitadores.

\section{DISCUSSÃO DOS RESULTADOS}

\section{Workshop de Portimão}

Em Portimão, considerando os parceiros envolvidos e a não aceitação da Câmara Municipal em ceder técnicos para a apresentação dos canais de participação, a primeira parte do Workshop ficou a cargo dos organizadores, tendo sido discutidos conceitos e definições sobre participação pública (incluindo a apresentação dos resultados quantitativos e qualitativos das subinvestigações realizadas), nos vários canais e as razões elencadas nas entrevistas e assinaladas nos inquéritos para a não participação, bem como, explicitadas algumas definições técnicas inerentes aos planos urbanísticos e que se reportam à carga construtiva dos terrenos, tendo inclusive sido utilizados alguns exemplos tridimensionais com formas diferentes para parâmetros urbanísticos iguais, com o intuito de esclarecer os participantes a precariedade de reduzir-se a qualidade urbana a parâmetros urbanísticos (como por exemplo nos Planos de Urbanização -PUs) [Figura 2]. 

Acrescido a isso, a experiência decorrente da ação em Portimão (mais especificamente a redução do público e a "falta de tempo" para concluir a parte prática), bem como, as sugestões dos parceiros locais, nomeadamente, as associações da sociedade civil, determinaram alterações no formato do Workshop relativamente ao de Portimão, passando a cingir-se à tarde de sábado, à seleção prévia das ideias a serem trabalhadas e ao preenchimento prévio de um modelo de Customer Journey Map criado por nós, com a ideia mais publicitada no anterior Workshop (que neste caso foi a retirada do trânsito automóvel do centro antigo, com a consequente criação de parques de estacionamento nos arredores da cidade, articulado com um sistema de mobilidade alternativo), para servir como exemplo para os grupos de trabalho. Aquando da realização do Workshop deparamo-nos com uma variável não planeada, para além dos parceiros, facilitadores e técnicos do Município, apenas estavam presentes dois (2) cidadãos, perfazendo um total de onze (11) participantes.

Diante do "novo" contexto, manteve-se o Workshop, mas alterou-se o foco de trabalho, ou seja, ao invés de trabalharmos a participação na ótica do cidadão, decidimos fazê-lo na ótica do Município. Ou seja, analisaram-se os processos participativos, procurando compreender quais os mecanismos e os procedimentos mais eficazes e quais os constrangimentos à participação pública.

Na primeira parte os organizadores apresentaram e fomentaram a discussão sobre os conceitos e as distintas tipologias de participação pública - ativa, semi-ativa e passiva -, incluindo a apresentação dos resultados quantitativos e qualitativos das sub-investigações realizadas sobre participação pública nos vários canais e das razões elencadas nas entrevistas e assinaladas nos inquéritos para a pouca participação pública. De seguida os técnicos municipais apresentaram as metodologias de participação no âmbito dos planos urbanísticos, as várias ferramentas digitais à disposição do cidadão no site do Município e o balanço da participação pública (em termos quantitativos e qualitativos) do orçamento participativo em Loulé, que já se encontra na quarta edição.

A discussão gerada foi bastante profícua porque incidiu sobre as inquietações dos agentes da Administração Pública, que cumprindo a agenda política, procuram sensibilizar a sociedade civil à participação, mas enfrentam problemas de várias dimensões. Entre eles podemos citar os seguintes:

- Necessidade de uma campanha de informação/ formação interna e externa (colaboradores do Município e público em geral) para a importância da utilização e "alimentação com dados", das plataformas digitais interativas do Município;

- Necessidade de sensibilização dos serviços internos para a atualização de informação/ prestação de contas dos conteúdos fornecidos nas plataformas digitais interativas do Município;

- Necessidade de simplificação da linguagem técnica no âmbito dos documentos urbanísticos sujeitos à discussão pública e da manipulação das plataformas digitais (que devem ser pensadas na ótica do utilizador);

- Necessidade de maior interação/ partilha entre os diversos serviços técnicos municipais, aquando da análise dos projetos candidatos ao Orçamento Participativo, para evitar constrangimentos futuros durante a execução;

- Necessidade de "formação para a cidadania ativa", em especial na apresentação dos projetos para o orçamento participativo. 
